\title{
Inactivation of micro-organisms isolated from infected lower limb arthroplasties using high-intensity narrow-spectrum (HINS) light
}

S. Gupta, Trauma \& Orthopaedics Southern General Hospital, 1345 Govan Road, Glasgow, G51 4TF and ROLEST, University of Strathclyde, Royal College Building, 204 George Street, Glasgow, G1 1XW, UK.

M. Maclean, ROLEST, University of Strathclyde, Royal College Building, 204 George Street, Glasgow, G1 1XW, UK.

J. G. Anderson, ROLEST, University of Strathclyde, Royal College Building, 204 George Street, Glasgow, G1 1XW, UK.

S. J. MacGregor, ROLEST, University of Strathclyde, Royal College Building, 204 George Street, Glasgow, G1 1XW, UK.

R. M. D. Meek, Trauma \& Orthopaedics, Southern General Hospital, 1345 Govan Road, Glasgow, G51 4TF, UK.

M. H. Grant, Department of Biomedical Engineering, University of Strathclyde, Wolfson Building, Glasgow G4 0NW, UK 


\begin{abstract}
High-Intensity Narrow-Spectrum (HINS) light is a novel blue light inactivation technology which kills bacteria through a photodynamic process, and is proven to have bactericidal activity against a wide range of species. Specimens from hip and knee arthroplasty infections were collected over a one year period. A range of these microbial isolates were tested for sensitivity to HINS-light. During testing, suspensions of the pathogens were exposed to increasing doses of HINS-light (of $123 \mathrm{~mW} / \mathrm{cm}^{2}$ irradiance). Non-light exposed control samples were also set-up. The samples were then plated onto agar plates and incubated at $37^{\circ} \mathrm{C}$ for 24 hours before enumeration.
\end{abstract}

Complete inactivation (greater than 4-log reduction) was achieved for all of the clinical isolates from infected arthroplasty cases. The typical inactivation curve showed a slow initial reaction followed by a period of rapid inactivation. The doses of HINS-light exposure required ranged from $118-2214 \mathrm{~J} / \mathrm{cm}^{2}$ respectively. Grampositive bacteria were generally found to be more susceptible than Gram-negative.

As HINS-light utilises visible-light wavelengths it can be safely used in the presence of patients and staff. This unique feature could lead to possible applications such as use as an infection prevention tool during surgery and post-operative dressing changes. 


\section{Introduction}

$\underline{\text { In England and Wales }}{ }^{1}$ there were over 186,000 hip and knee arthroplasty operations performed in 2013, with a further 14,000 such procedures performed in Scotland the previous year ${ }^{2}$. Prosthetic infection is a major but infrequent complication of the surgery, with a relatively unchanged incidence in recent years of between $0.6 \%$ and $2 \%$ per joint per year ${ }^{3-5}$. Revision of infected implants is associated with substantial morbidity and has significant economic implications. Any new developments in reducing the burden of prosthetic joint infection are welcome.

The potential of antimicrobial light technologies have previously been considered. The absorption of ultraviolet (UV) light photons (wavelengths 100-400 nm) leads to photobiochemical reactions that cause damage to nucleic acids, with a single photon having the potential to induce a lethal effect ${ }^{6,7}$. However, this effect is often nondiscriminatory, and UV light has recognised significant adverse side effects including dermatological (neoplasms) and ophthalmological (cataracts) conditions ${ }^{8}$. As a result of these safety issues, individuals cannot be directly exposed to UV light disinfection technologies.

HINS-light is a narrow band of visible blue light, with peak wavelength of $405( \pm 5)$ $\mathrm{nm}$ that has been developed by researchers in The Robertson Trust Laboratory for Electronic Sterilisation Technologies (ROLEST) at the University of Strathclyde. The technology induces inactivation of a range of bacterial pathogens via a photodynamic inactivation effect which is triggered by absorption of the light. This leads to photo-excitation of endogenous porphyrins and the production of reactive 
oxygen species, primarily singlet oxygen. The subsequent result of this is bacterial cell death ${ }^{9}$. A series of studies by the ROLEST team have proven the germicidal efficacy of HINS-light against a range of bacteria in a variety of laboratory and clinical settings ${ }^{10-13}$. The purpose of this study was to investigate if HINS-light technology could successfully kill microorganisms isolated from cases of infected lower limb arthroplasty.

\section{Materials and methods}

\section{Microbiological Methodology}

Isolates from clinically relevant arthroplasty infections were prospectively gathered over a one year period. At the Southern General Hospital microbiology lab, when a positive culture was identified, the isolate was transferred onto Microbank ${ }^{\mathrm{TM}}$ beads (ProLab Diagnostics) containing cryopreservative solution for storage at $-70^{\circ} \mathrm{C}$ in the hospital freezer. The isolates for testing for susceptibility to HINS-light were then transferred to ROLEST. There were a total of 51 positive cultures (Table I).

For recovery of the microbial isolate, an inoculated Microbank bead was removed under aseptic conditions and streaked onto an agar plate. The agar medium of choice was selected dependent on the organism being cultured (Table II). This streaked plate was then incubated at $37^{\circ} \mathrm{C}$ for 18 hours. The purity of the isolates was verified by Gram staining and visual identification under the microscope.

In order to culture a microbial strain for experimental use, a loopful of organism from the agar slope (stored at $4^{\circ} \mathrm{C}$ ) was aseptically extracted and inoculated into $100 \mathrm{ml}$ broth using a sterile wire loop. The broth was then incubated to provide a population 
of approximately $10^{9}$ colony-forming units per millilitre (CFU/ml). The inoculated broth was then centrifuged and serially diluted to the population density required for testing (approximately $10^{5} \mathrm{CFU} / \mathrm{ml}$ ). The diluted solutions produced were clear, with no turbidity.

All clinical isolates were successfully cultured with the exception of the Streptococcus isolates. Several attempts to culture for experimental use proved unsuccessful; therefore the effect of HINS-light on streptococcal inactivation could not be observed in this study. In addition, other CNS were not tested for their sensitivity to HINS-light, as the species were not defined. This study aimed to test a microorganism from each genus and/or species highlighted in Table II. The bacterial and yeast strains selected for testing are listed (Table III), along with the respective non-identifiable patient background data.

\section{HINS-light source}

Light-emitting diodes (LED) provide a much higher intensity light emission when used as arrays rather than single units. A $405 \mathrm{~nm}$ 99-DIE LED array (Opto Diode Corp., California, USA) was used in this study. This is composed of 99 LEDs (9 x 11 rectangle) closely packed. This array has an area of $3.2 \mathrm{~cm}^{2}(2 \times 1.6 \mathrm{~cm})$ and is powered by a DC supply (HQ POWER) with a controllable output in the range $0-3$ A and $0-15 \mathrm{~V}$. It emits violet light across a narrow spectral region and is made from indium-gallium-nitride. The $405 \mathrm{~nm}$ LED array has a centre wavelength (maximum emission) close to $405 \mathrm{~nm}$, and the bandwidth is $\sim 10 \mathrm{~nm}$ at full-width half-maximum (Fig. 1). Though LEDs are known to have minimal heat dissipation, a heatsink and cooling fan were attached to the LED array as a precautionary measure. This ensured 
that a stable temperature around the LED array was maintained throughout testing. The LED array unit was mounted in PVC housing, and this unit was used for all microbial suspension experiments.

\section{Experimental arrangement for exposure of microbial suspensions}

A Gilson pipette and sterile tip was used to transfer $3 \mathrm{ml}$ of the liquid bacterial sample to the central well within a 12 -well multidish (Nunc, Denmark). A $7 \mathrm{~mm} \times 2 \mathrm{~mm}$ magnetic follower (Fisher Scientific) was added to the sample. The multidish was then placed onto a magnetic stirrer (Yellowline MSH Basic), ensuring continuous mechanical agitation of the sample during light exposure. The 99-DIE LED array, fan and PVC housing unit were then placed directly over the well containing the suspension to be exposed. The underside of the housing unit had an outer edge that fitted around the multidish, ensuring it was firmly held in place. The HINS light input current was set at $1 \mathrm{~A}(+/-0.05)$, with a voltage of $11.5 \mathrm{~V}(+/-0.25)$ leading to irradiance from the LED array of $123 \mathrm{~mW} / \mathrm{cm}^{2}$. The distance between the sample and the LED array was approximately $2 \mathrm{~cm}$, thus keeping the light intensity constant for all exposures. The complete HINS-light exposure set-up with all components can be seen in Figure 2.

A control sample was set-up for each test. This was a bacterial suspension held in the well of a multidish which was mechanically agitated for the same period of time as the test sample under normal laboratory light conditions, but not exposed to $405 \mathrm{~nm}$ light. Following exposure at the various time settings, samples were plated onto agar plates (the type dependent on the organism being tested - Table II) using a WASP 2 
spiral plater (Don Whitley Scientific). The plates were then incubated at $37^{\circ} \mathrm{C}$ for 24 hours before enumeration. All of the experiments were repeated at least once.

\section{Results}

Complete inactivation was achieved for all of the clinical isolates from infected arthroplasty cases. A graph comparing the inactivation kinetics for all the Grampositive bacteria exposed to $405 \mathrm{~nm}$ HINS-light is shown in Figure 3 . With the exception of E. faecalis, all of the Gram positive bacteria were successfully inactivated in under an hour, with an approximate $5 \log _{10}$ reduction achieved in each case. S. epidermidis was the quickest to be completely inactivated in 16 minutes, followed closely by $S$. aureus which took 20 minutes. E. faecalis was the slowest to be inactivated, taking around 120 minutes.

The inactivation times for the Gram-negative organisms were clearly longer than those for the Gram-positive bacteria (Fig. 4). The longest time required for inactivation was 5 hours of $405 \mathrm{~nm}$ light exposure; and this was for E.coli. The other enterobacteriaceae, namely $K$. pneumoniae and $S$. marcescens, required slightly shorter exposure times of 3 and 4 hours respectively for complete inactivation. $P$. aeruginosa was the last Gram-negative organism tested, and was found to be inactivated quickest, over the course of 90 minutes. C. albicans was the sole yeast isolate exposed to HINS-light, and a clear $4 \log _{10}$ reduction was apparent after 45 minutes (Fig. 5). The control line was unremarkable and flat throughout, similar to what was seen with all of the other control samples. 
When the irradiance and exposure time of the HINS-light applied to the microorganisms is known, the dose applied for complete inactivation may be calculated based on the formula:

\section{$\mathbf{E}($ energy or dose $)=\mathbf{P}($ power or irradiance $) \times \mathbf{t}($ time, in seconds $)$}

Based on the experimental results for the HINS-light exposure of microbial suspensions, the inactivation capability of the $405 \mathrm{~nm}$ HINS-light can be quantified. This is known as the germicidal efficiency (GE). This can be defined as the $\log _{10}$ reduction of a given microbial population by inactivation per unit of light energy density in $\mathrm{J} / \mathrm{cm}^{2}$, also known as the dose $\mathrm{e}^{14}$. This calculation can be shown as:

\section{Germicidal Efficiency, $\eta=\log _{10}\left(\mathrm{~N} / \mathrm{N}_{0}\right)$ per $\mathrm{J} / \mathrm{cm}^{2}$}

Table IV provides a summary of the GE of the $405 \mathrm{~nm}$ light emitted from the 99-DIE LED array for all the pathogens tested.

\section{Discussion}

New advances to aid in the prevention or management of prosthetic joint infection are welcome. HINS-light is a novel visible blue light technology which achieves the inactivation of pathogens via a photodynamic inactivation effect, which is triggered by absorption of the light and is mediated by porphyrins ${ }^{12}$. In this study, the sensitivity of clinical isolates from hip and knee arthroplasty infections to HINS-light 
was examined. Pathogens that could be cultured and identified were exposed to HINS-light, with all inactivated using $405 \mathrm{~nm}$ light. S. epidermidis was the bacteria inactivated in the shortest period of time, 16 minutes. This Gram-positive bacterium required the lowest dose of all those tested, and as a result had the highest GE. E. coli took the longest period of time to achieve complete inactivation, 300 minutes. This Gram-negative bacterium therefore required the highest dose of all those tested, and in turn had the lowest GE. Murdoch et $\mathrm{al}^{11}$ found the GE of E. coli $\mathrm{O} 157: \mathrm{H} 7$ exposed to $405 \mathrm{~nm}$ light to be 0.02 , ten times greater efficiency than what we noted. This may be due to differences in the exact nature of the light source used in each study, leading to variations in the emission and peak wavelengths from each source. Alternatively, this may simply be a reflection on the different bacterial strains examined in the separate studies.

The Gram-positive bacteria were generally noted to require lower doses of HINS-light exposure to achieve inactivation in comparison to the Gram-negative bacteria. This was similar to what has previously been published in 2009 by Maclean et al ${ }^{10}$. The authors of that paper suggested that Gram-positive bacteria produce greater quantities of porphyrins, and specifically coproporphyrin, making them more readily inactivated by visible light than Gram-negative bacteria. The enteric bacteria were noted to be the least responsive to HINS-light. This may represent inherent resilience from their natural gut habitat. The only yeast tested was $C$. albicans, and it was seen to behave in a manner more similar to the Gram-positive bacteria than Gram-negative, with respect to inactivation dosages and GE. 
The suspension inactivation curves for the bacteria followed a similar shape. There was an initial period of inactivity, followed by a rapid acceleration until complete inactivation. The distinct inactivation times observed may be explained by the fact that different bacteria produce different porphyrins, the peak absorption wavelengths are therefore likely to vary, and in turn different wavelengths may be required for optimum photostimulation ${ }^{10}$.

Differing mechanisms of bacterial inactivation between blue light (porphyrins mediated) and UV light (DNA damage) are emphasised when our work is compared to the landmark publication of Chang et $\mathrm{al}^{15}$. The authors conducted a series of experiments using a collimated beam of UV light set at $254 \mathrm{~nm}$ and found that Gramnegative bacteria were more susceptible than Gram-positive bacteria. This is the opposite of the results with HINS-light thus far. Furthermore, the study ${ }^{15}$ reports that the dosage of UV light required for a $5-\log _{10}$ reduction of both S. aureus and E. coli was approximately $10 \mathrm{~mW}-\mathrm{sec} / \mathrm{cm}^{2}$. Not only is this considerably less than any of the dosages required involving $405 \mathrm{~nm}$ blue light, but the dosage of UV light required for inactivation of both bacteria was similar. We acknowledge that visible light inactivation is much less efficient than UV-inactivation, but highlight the greater operational safety it offers. Furthermore, recent studies have shown that therapeutic $\underline{\text { doses of HINS-light does not adversely affect in vitro models of wound healing }{ }^{16} \text { and }}$ that the technology is potentially effective against biofilm ${ }^{17}$.

This study provides further support for the anti-microbial properties of HINS-light, specifically addressing isolates from infected arthroplasty specimens. Future work assessing the efficacy of $405 \mathrm{~nm}$ light in the presence of blood and pus, as well as 
further work on biofilm decontamination are planned. This would potentially help differentiate whether the light is useful for the treatment of infection, or only in prevention. Potential intraoperative roles for HINS-light include direct application to the wound or to the prosthesis prior to insertion, minimising implant associated infection. At present the technology is being used for environmental decontamination of isolation rooms in the Canniesburn Plastic Surgery Unit ${ }^{13}$. Pending further development of the technology, HINS-light may help prevent infection in orthopaedic operating theatres and beyond. 


\section{References}

1. No authors listed. National Joint Registry for England \& Wales: $10^{\text {th }}$ Annual report, 2013. http://www.njrcentre.org.uk (last accessed 28 August 2014)

2. No authors listed. Scottish Arthroplasty Project: Biennial report, 2012. http://www.arthro.scot.nhs.uk (last accessed 28 June 2014)

3. Phillips JE, Crane TP, Noy M, Eliott TS, Grimer RJ. The incidence of deep prosthetic infections in a specialist orthopaedic hospital: a 15-year prospective survey. J Bone Joint Surg [Br] 2006; 88: 943-8.

4. Jamsen E, Huhtala H, Puolakka T, Moilanen T. Risk factors for infection after knee arthroplasty. A register-based analysis of 43,149 cases. J Bone Joint Surg [Am] 2009; 91: 38-47.

5. Namba RS, Inacio MC, Paxton EW. Risk factors associated with surgical site infection in 30,491 primary total hip replacements. J Bone Joint Surg [Br] 2012; 94:1330-8.

6. Block SS. Disinfection, Sterilisation and Preservation. Fifth Ed. Philadelphia: Lippincott Williams \& Wilkins, 2001.

7. Sinha RP, Häder DP. UV induced DNA damage and repair: a review. Photochemical and Photobiological Sciences 2002; 1: 225-236.

8. Bolashikov ZD, Melikov AK. Methods for indoor air disinfection and purification from airborne pathogens for application in HVAC systems. The sixth international conference on indoor air quality, ventilation \& energy conservation in buildings environment and energy 2007; 2: 565-573. 
9. Maclean M, MacGregor SJ, Anderson JG, Woolsey G. High-intensity narrowspectrum light inactivation and wavelength sensitivity of Staphylococcus aureus. FEMS Microbiol Lett 2008; 285: 227-232.

10. Maclean M, MacGregor SJ, Anderson JG, Woolsey G. Inactivation of Bacterial Pathogens following Exposure to Light from a 405-Nanometer LightEmitting Diode Array. Applied and Environmental Microbiology 2009; 75: 19321937.

11. Murdoch LE, Maclean M, MacGregor SJ, Anderson JG. Inactivation of Campylobacter jejuni by Exposure to High-Intensity 405-nm Visible Light. Foodborne Pathogens and Disease 2010; 7: 1211-1216.

12. Maclean M, MacGregor SJ, Anderson JG et al. Environmental decontamination of a hospital isolation room using high-intensity narrowspectrum light. Journal of Hospital Infection 2010; 26: 247-51.

13. Bache SE, Maclean M, MacGregor SJ et al. Clinical studies of the HighIntensity Narrow-Spectrum light Environmental Decontamination System (HINSlight EDS), for continuous disinfection in the burn unit inpatient and outpatient settings. Burns 2012; 38: 69-76.

14. Wang T, MacGregor SJ, Anderson JG, Woolsey GA. Pulsed ultra-violet inactivation spectrum of Escherichia coli. Water Research 2005; 39: 2921-2925.

15. Chang JC, Ossoff SF, Lobe, DC et al. UV inactivation of pathogenic and indicator microorganisms. Applied and Environmental Microbiology 1985; 49: $1361-5$

16. McDonald R, MacGregor SJ, Anderson JG, Maclean M, Grant MH. Effect of 405-nm high-intensity narrow-spectrum light on fibroblast-populated collagen 
lattices: and in vitro model of wound healing. Journal of Biomedical Optics 2011; 16: 048003-1-4.

\section{McKenzie $\quad$ K, Maclean $\quad$ M, Timoshkin IV, Endarko E, MacGregor} SJ, Anderson JG. Photoinactivation of bacteria attached to glass and acrylic surfaces by $405 \mathrm{~nm}$ light: potential application for biofilm decontamination. Photochem Photobiol 2013;89(4):927-35. 
Table I Positive cultures grown from infected lower limb arthroplasty over one year from the Southern General Hospital Department of Microbiology

\begin{tabular}{|c|c|c|}
\hline $\begin{array}{c}\text { Gram Stain } \\
\text { Result }\end{array}$ & Microorganism & Positive cultures $n=51$ \\
\hline+ & Staphylococcus aureus & 23 \\
\hline+ & Coagulase negative Staphylococcus & 6 \\
\hline+ & Staphylococcus epidermidis & 2 \\
\hline+ & Corynebacterium striatum & 2 \\
\hline+ & Enterococcus species & 1 \\
\hline+ & Enterococcus faecalis & 1 \\
\hline+ & Micrococcus species & 1 \\
\hline+ & Streptococcus species & 1 \\
\hline+ & Group B Streptococcus & 1 \\
\hline+ & Streptococcus pneumoniae & 1 \\
\hline- & Escherichia coli & 4 \\
\hline- & Klebsiella pneumoniae & 4 \\
\hline- & Pseudomonas aeruginosa & 2 \\
\hline- & Serratia marcescens & 1 \\
\hline N/A & Candida albicans & 1 \\
\hline
\end{tabular}


Table II The bacterial and yeast strains selected for experimental use listed along with the appropriate culture medium

\begin{tabular}{|l|l|}
\hline Microorganism & Growth Media \\
\hline Staphylococcus aureus & Nutrient Broth \& Agar \\
\hline Staphylococcus epidermidis & Tryptone soya Broth \& Agar \\
\hline Corynebacterium striatum & Brain Heart Infusion Broth \& Blood Agar \\
\hline Enterococcus faecalis & Nutrient Broth \& Agar \\
\hline Micrococcus species & Nutrient Broth \& Agar \\
\hline Streptococcus species & Brain Heart Infusion Broth \& Blood Agar \\
\hline Escherichia coli & Nutrient Broth \& Agar \\
\hline Klebsiella pneumoniae & Nutrient Broth \& Agar \\
\hline Serratia marcescens & Nutrient Broth \& Agar \\
\hline Pseudomonas aeruginosa & Nutrient Broth \& Agar \\
\hline Candida albicans & Malt extract Broth \& Agar \\
\hline
\end{tabular}


Table III Details of the bacterial and yeast isolates from infected THR/TKR selected for experimental use

\begin{tabular}{|l|c|c|l|}
\hline Microbial Isolate & $\begin{array}{c}\text { Patient Age } \\
\text { (Years) }\end{array}$ & Gender & Source \\
\hline Staphylococcus aureus & 67 & Male & Right knee tissue \\
\hline Staphylococcus epidermidis & 68 & Male & Right knee swab \\
\hline Corynebacterium striatum & 75 & Female & Right hip tissue \\
\hline Enterococcus faecalis & 68 & Male & Right knee tissue \\
\hline Micrococcus species & 80 & Female & Left hip tissue \\
\hline Streptococcus species & 57 & Female & Left knee tissue \\
\hline Escherichia coli & 71 & Male & Right knee swab \\
\hline Klebsiella pneumoniae & 81 & Male & Left hip swab \\
\hline Serratia marcescens & 64 & Male & Right hip aspiration \\
\hline Pseudomonas aeruginosa & 62 & Male & Right knee swab \\
\hline Candida albicans & 79 & Female & Left hip swab \\
\hline
\end{tabular}


Table IV Germicidal efficiency of 99-DIE LED array against pathogens isolated

\begin{tabular}{|c|c|c|c|c|c|}
\hline Microorganism & $\begin{array}{l}\text { Exposure } \\
\text { Time (s) }\end{array}$ & $\begin{array}{c}\text { Power Density } \\
\qquad\left(\mathbf{m W} / \mathbf{c m}^{2}\right)\end{array}$ & $\begin{array}{c}\text { Dose } \\
\left(\mathrm{J} / \mathrm{cm}^{2}\right)\end{array}$ & $\begin{array}{c}\log _{10} \\
\text { Reduction }\end{array}$ & $\begin{array}{l}\text { Germicidal Eff } \\
\left(\log _{10}\left(N / N_{0}\right) /\right.\end{array}$ \\
\hline S. aureus & 1200 & 123 & 147.6 & 5.16 & 0.0350 \\
\hline S. epidermidis & 960 & 123 & 118.1 & 5.12 & 0.0434 \\
\hline C. striatum & 1800 & 123 & 221.4 & 5.02 & 0.0227 \\
\hline E. faecalis & 7200 & 123 & 885.6 & 4.72 & 0.0053 \\
\hline Micrococcus & 3600 & 123 & 442.8 & 4.85 & 0.0110 \\
\hline
\end{tabular}

$\begin{array}{lccccc}\text { E. coli } & 18000 & 123 & 2214 & 5.01 & 0.0023 \\ \text { K. pneumoniae } & 10800 & 123 & 1328.4 & 5.05 & 0.0038 \\ \text { S. marcescens } & 14400 & 123 & 1771.2 & 5.26 & 0.0030 \\ P . \text { aeruginosa } & 5400 & 123 & 664.2 & 5.00 & 0.0075\end{array}$

C. albicans

2700

123

332.1

4.52

0.0136 


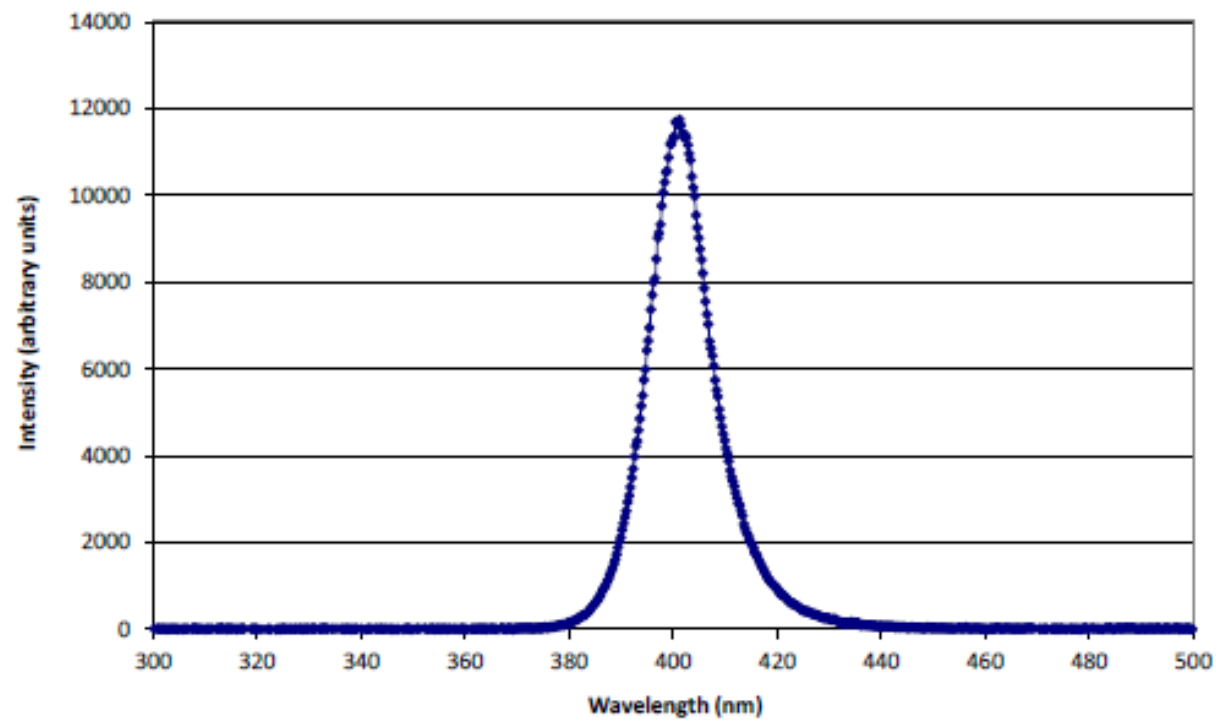

Figure 1 Emission spectrum of the 99-DIE $405 \mathrm{~nm}$ light emitting diode array

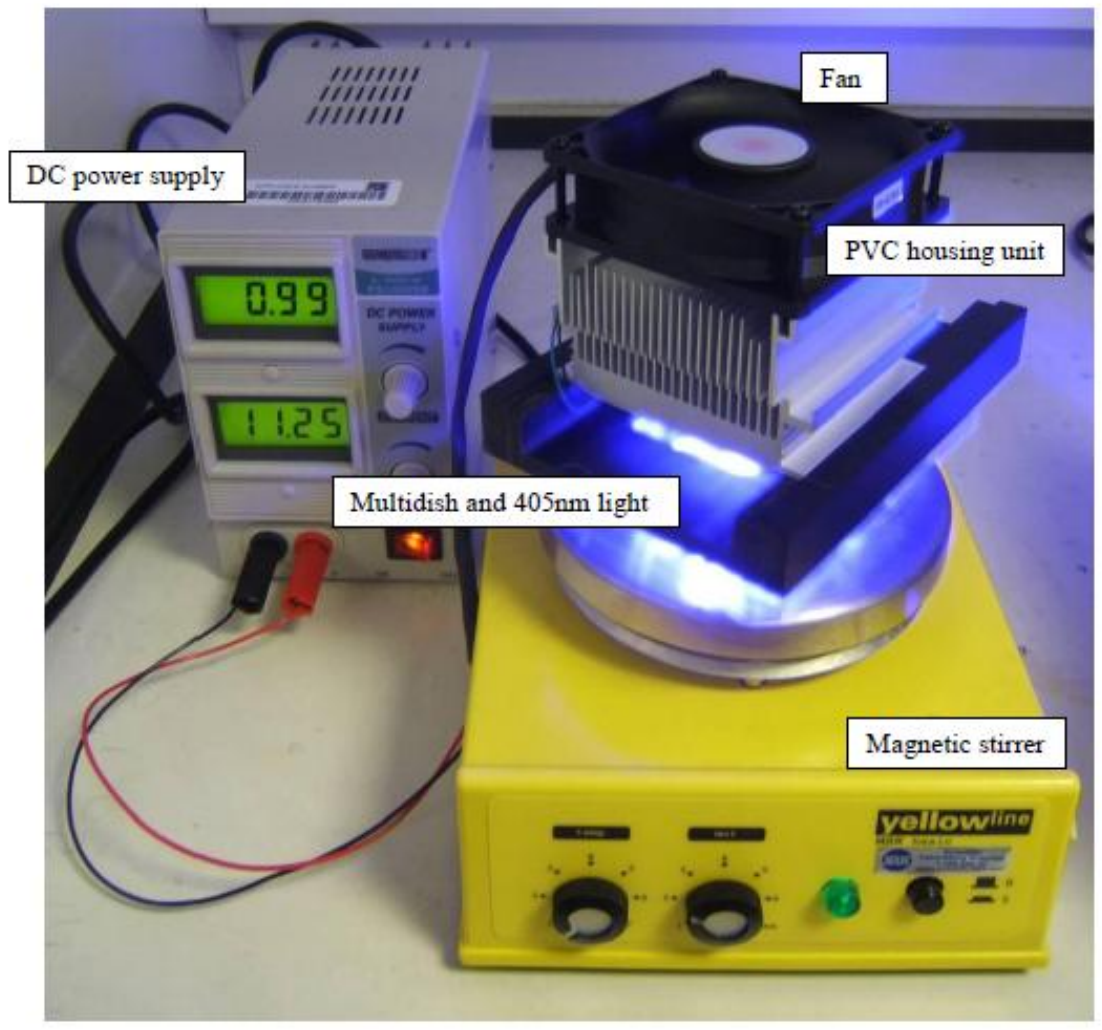

Figure 2 High-intensity narrow-spectrum light treatment system for exposure of bacterial suspensions 


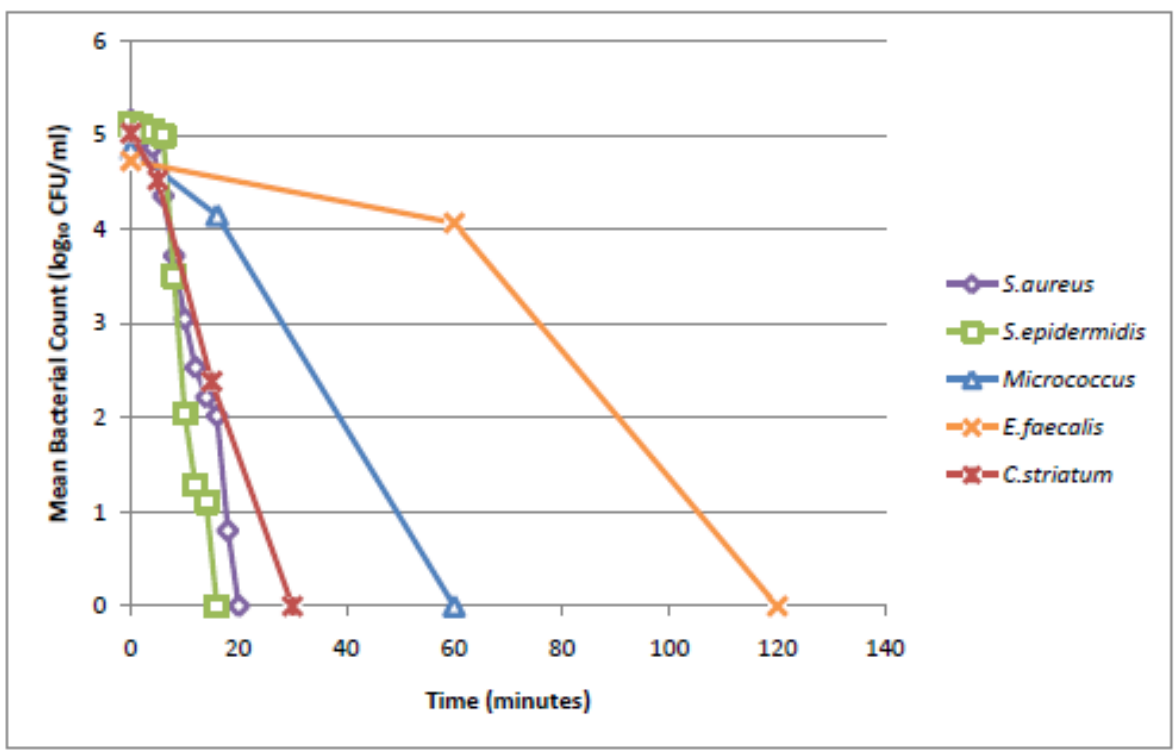

Figure 3 Comparison of the kinetics for High-intensity narrow-spectrum light inactivation of the Gram-positive bacterial isolates in suspension $\left(123 \mathrm{~mW} / \mathrm{cm}^{2}\right.$ irradiance).

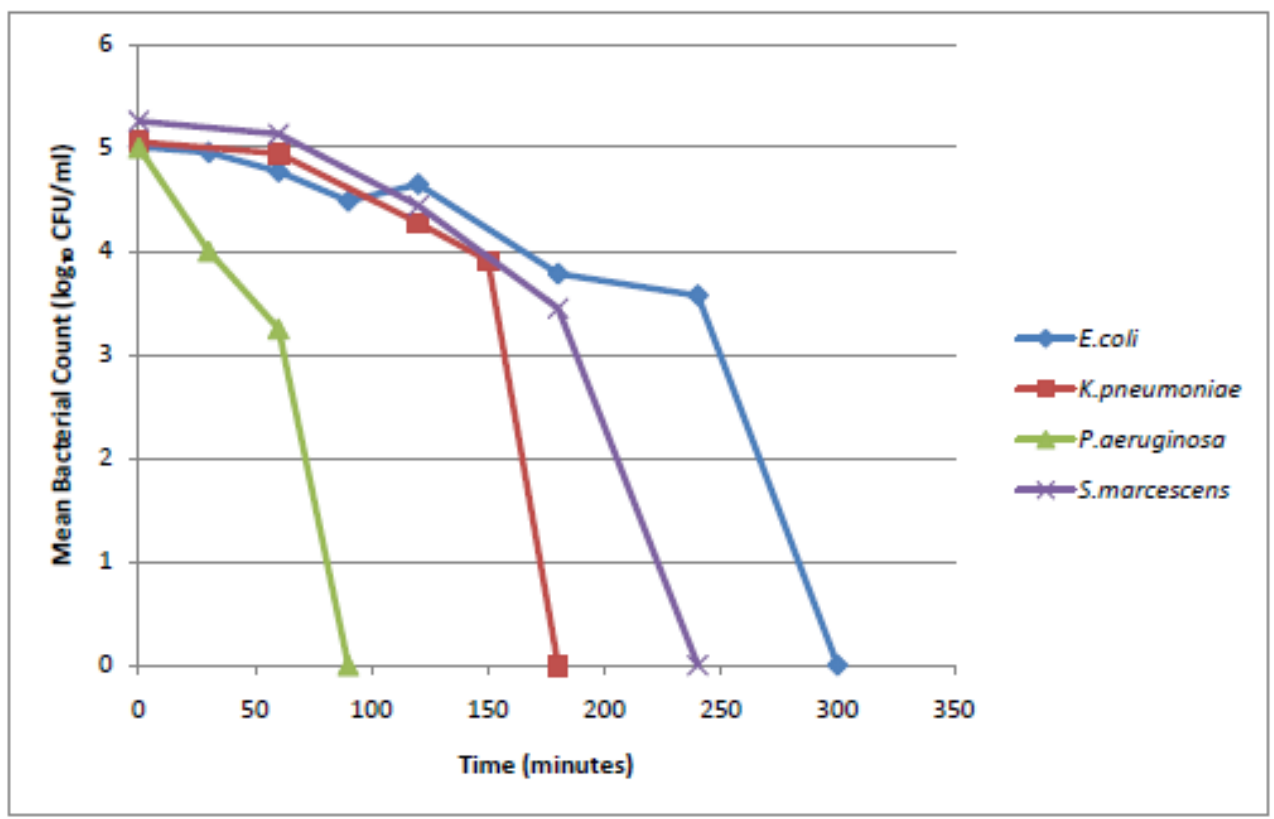

Figure 4 Comparison of the kinetics for High-intensity narrow-spectrum light inactivation of the Gram-negative bacterial isolates in suspension $\left(123 \mathrm{~mW} / \mathrm{cm}^{2}\right.$ irradiance). 


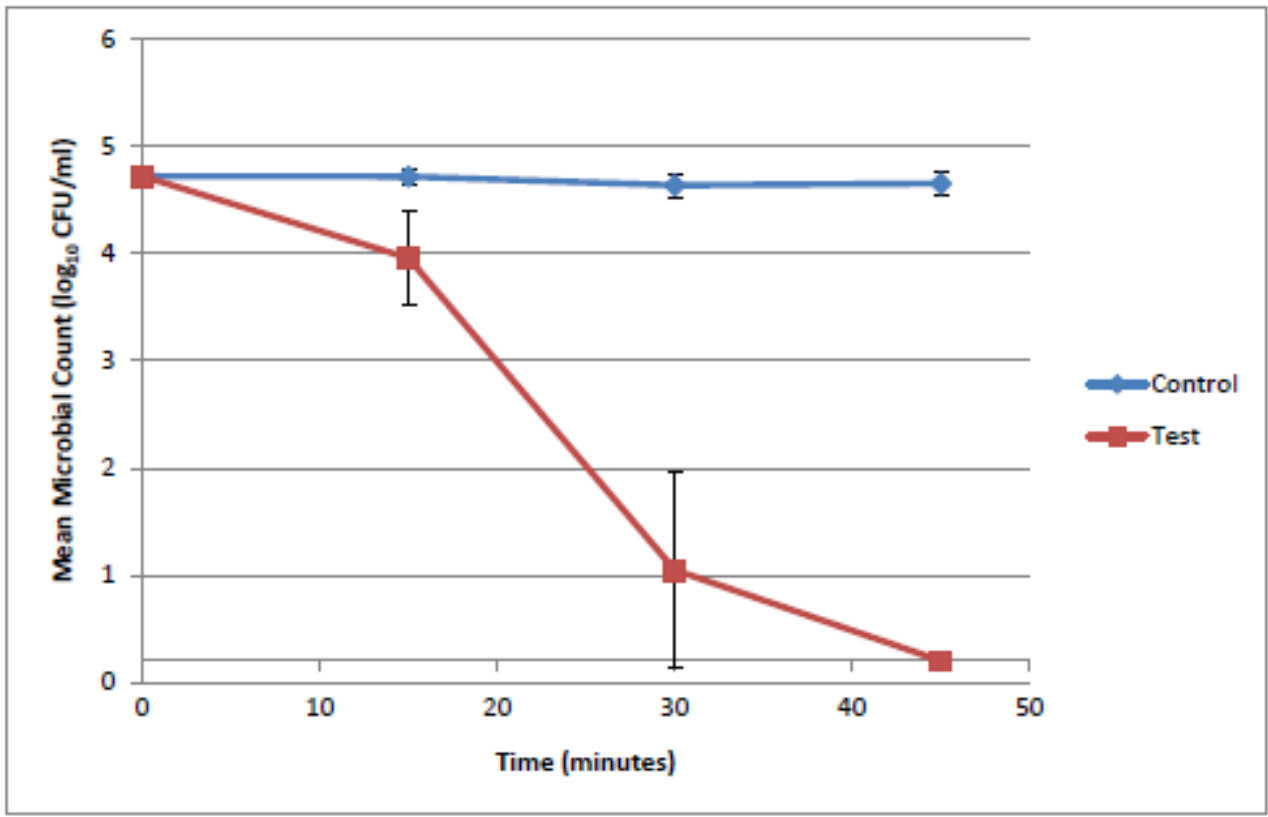

Figure 5 Inactivation of Candida albicans in suspension by High-intensity narrowspectrum light exposure $\left(123 \mathrm{~mW} / \mathrm{cm}^{2}\right.$ irradiance $)$. 